\title{
A luz cênica como visão espiritual: Gordon Craig e o design por símbolos
}

The scenic lighting as spiritual vision: Gordon Craig and design by symbols

Alberto Luiz Morgado ${ }^{1}$

Paulo César Balardim Borges ${ }^{2}$ 


\section{Resumo}

O seguinte trabalho investiga a concepção de iluminação cênica de Gordon Craig e sua influência na cena contemporânea. Para tanto, são levadas em consideração as sombras como forma de expressão, a influência de Richard Wagner e o pós-impressionismo. Por fim, analisamos a produção de Dido and Aeneas, marco da iluminação cênica moderna.

Palavras-chave: Gordon Craig; design; iluminação cênica

\section{Abstract}

The following work investigates Gordon Craig's conception of scenic lighting and its influence on the contemporary scene. To that end, the shadows as a form of expression, the influence of Richard Wagner and post-impressionism are taken into account. Finally, we analyze the production of Dido and Aeneas, landmark of modern scenic lighting.

Keywords: Gordon Craig; design; scenic lightning

ISSN: 1414.5731

E-ISSN: 2358.6958

\footnotetext{
${ }_{1}^{1}$ Mestrando no Programa de Pós-Graduação em Artes Cênicas (PPGT), da Universidade do Estado de Santa Catarina (UDESC)). albertoluizmorgado@gmail.com ${ }^{2}$ Prof. Dr. Adjunto atuando na graduação e na pós-graduação em teatro (PPGT) do Centro de Artes (CEART), da Universidade do Estado de Santa Catarina (UDESC). Diretor, ator, e cenógrafo da companhia teatral Caixa do Elefante Teatro de Bonecos. paulobalardim@gmail.com
} 


\section{O conceito}

A concepção cênica de Gordon Craig (1872-1966) é simples, despojada e eficiente; para ele - adepto do movimento Simbolista - a cena naturalista é disfuncional, impõe a tarefa de transformar a cena em uma infinidade de objetos cênicos e telões pintados que pretensamente evocariam o real, transformando, às vezes, o palco num museu. Para Craig era primordial suprimir o que há de obsoleto na mise-en-scène. O naturalismo, facsimile da natureza refrata a imaginação, desdenha da capacidade criativa do espectador; neste contexto, não há espaço para a invenção, para a poesia. O Naturalismo, como toda cópia, é despojada de conteúdo simbólico. Designer por excelência, Craig desenvolveu uma arquitetura que insinua um prolongamento, um continuum espacial; luz, linhas, cores em coesão e harmonia com o espaço cênico: um ambiente simbólico. Síntese do impacto da sua iluminação, Scott Palmer anota a respeito da iluminação em Dido and Aeneas em (maio de 1900) sob a direção de Craig:

Por inexistir as luzes da ribalta, os atores pareciam menos artificiais. As telas laterais iluminadas de Herkomer, fixadas a dois ou mais metros à frente do pano de fundo, tinham alcançado uma tal profundidade de cor que ele, Craig, jamais tinha visto antes; pois só tinha conhecimento das telas pintadas que eram usadas em cenas de pantomima. Decidiu que, qual fosse o motivo, usaria telas também, com luzes laterais de diferentes cores. O resto da sua iluminação viria por cima do proscênio (Palmer, 2012, pp. 2-3).

\section{Influências}

Hubert von Herkomer (1849-1914) foi um multitalentoso artista: pintor, compositor, músico, diretor teatral e também um dos pioneiros na direção de cinema; alemão, de origem bastante humilde se fixou em Bushey, interior da Inglaterra onde possuía um estúdio. A privação material que ele e sua família passaram repercutiu manifestamente em sua concepção artística, tornando-se um ferrenho abnegado pelo realismo; seus trabalhos têm a marca do humanismo; em 1907 tornou-se cavaleiro por Edward VII. Craig frequentou assiduamente seus cursos e experimentos, e por mais que tivessem abordagens artísticas diferentes - Craig era um pós-impressionista - a sua influência é inegável. Nos seus trabalhos posteriores, principalmente, em Dido and Aeneas, Craig, evoluiu substancialmente tanto na cenografia, quanto na iluminação; neste trabalho ele onde fez uso de luzes laterais de diversas cores, aboliu as luzes de ribalta, como também, fez uso da gaze (light gauzes) com efeito similar ao tule, gerando excelentes efeitos de transparência e dotada de grande sensibilidade à luz (Palmer, 2012, pp. 2-3).

Outro nome proeminente no estudo da cena foi o suíço Adolphe Appia (18621928), ele e Craig fizeram parte do New Stagecraft Movement, entretanto, nunca trabalharam juntos e o contato pessoal foi quase nenhum, mas se comunicavam às vezes por cartas e teciam considerações reciprocamente sobre suas concepções artísticas. Craig se concentrava no impacto visual da sua mise-en-scène enquanto Appia investigava o equilíbrio entre a tridimensionalidade do corpo do ator e a antinonímia deste com o cenário bidimensional. Em Appia, o ator é o elemento proeminente da sua abor- 
dagem artística. Em Craig, o ator é um componente, uma unidade pictórica que deveria ser substituída pela metáfora do über-marionette. Concordavam no fundamento de que a plasticidade e a luz andavam lado-a-lado, foi o que se convencionou chamar Teoria da Plasticidade. Ambos são sinônimos de alto design, tecnologia e modernidade na cena teatral. As produções operísticas e teatrais contemporâneas - principalmente nas óperas de Richard Wagner - são caudatárias da contundência expressiva de Appia.

$\mathrm{Na}$ formulação de Craig, há uma tentativa de reelaborar o conceito wagneriano de "teatro como obra de arte total" (gesamtkunstwerk), abordagem bem conhecida que estabelece a fusão da música, cenografia, iluminação, dança, arquitetura, pintura e representação dramática. Em Da Arte do Teatro (1963) Craig formula uma associação entre sinestesia (uma espécie de 'cruzamento sensorial') e a gesamtkunstwerk. No entanto, a concepção de Craig não se confunde com a de Wagner, pois baseia-se na integração dos elementos que compõem a cena, isto é, luz, linhas, palavras, gestos, símbolos-signos, mise-en-scène e etc., e não a incorporação de todas as manifestações artísticas propostas pelo compositor. Para Craig (apud Symons, 1907, p. 233) a arte é um ato vital, expressão do ser, da mesma forma que o ser é expressão da natureza. Arte que se revela no impulso que instiga a Vida para a arte. Indicativo onde emerge o inconsciente, primado do Simbolismo.

Longe da concepção cênica naturalista, a luz sob Craig aproxima-se de uma arquitetura funcional, banindo assim tudo aquilo que remetesse à ideia de ornamento, adorno. Dentro da sua proposta de uma 'Nova Cena' a luz, efetivamente, torna-se um novo elemento, um componente ativo que irá privilegiar a plasticidade, o movimento: um moto-palco abstrato, mutável, deslizante, de movimento real ou não. Craig suprimiu o palco-plano, os 'cenários-caixa' e os seus telões paisagísticos pintados. Sua estética fundada no Simbolismo almeja o que está além da aparência, do superficial, um lugar e estado onde se descortina a poesia da vida; a verdade não é ostensiva, revela-se por meio de símbolos, um locus indicativo de transcendência onde a poesia entra em movimento. Para ele, o movimento perfeito (ou gesto simbólico) criaria uma união mística com os ritmos universais da natureza, um caminho primevo onde diretamente se exprimiria alma.

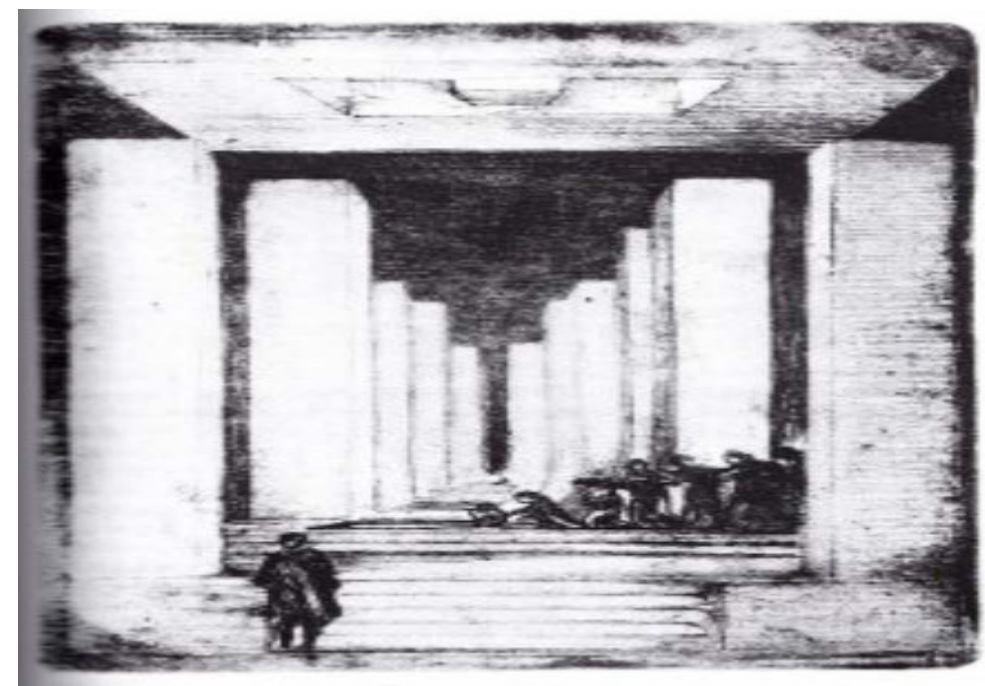

Figura 2: Set. Fonte: https://progenytheatre.blogs.lincoln.ac.uk/2013/02/07/artistic-influences/ Acesso em: 05 fev. 2018, 
Na figura 2 acima, Set, desenhado por Craig, nota-se a preocupação com a verticalidade, a perspectiva, a profundidade da cena. Incomodava Craig os cabos da iluminação elétrica, mas não queria substituir esse tipo de luz. Para ele, mais do que estar atualizado com relação à luz, à maquinaria, era fazer o melhor (grifo dele). Mesmo assim, diz ele, nada se comparava à luz do dia, que ainda não teve (no teatro) o seu dia (Craig, 1919, p. 29).

A luz cênica na concepção de Craig sofreu influência também do Wayang (ou Wajang), uma forma de representação de formas animadas encontradas no sudeste asiático, em especial, na Indonésia. É um teatro de sombras com bonecos (figura abaixo), em seu repertório encontramos tesouros do cânon hindu como o Mahabharata e o Ramayana e também textos com abordagens fundadas no mito. $O$ manipulador (Dalang) é um artista e uma autoridade espiritual. No Wayang kulit (espécie de Wayang com bonecos em couro) tradicionalmente o espetáculo começa às nove da noite e termina às cinco da manhã. Sobre o Wayang, Sangga Sarana Persada comenta que as histórias têm índole moral: a honestidade e verdade contra o mal, como também, escolher de acordo com suas crenças e a purificação da alma (Persada, 1997-2000).

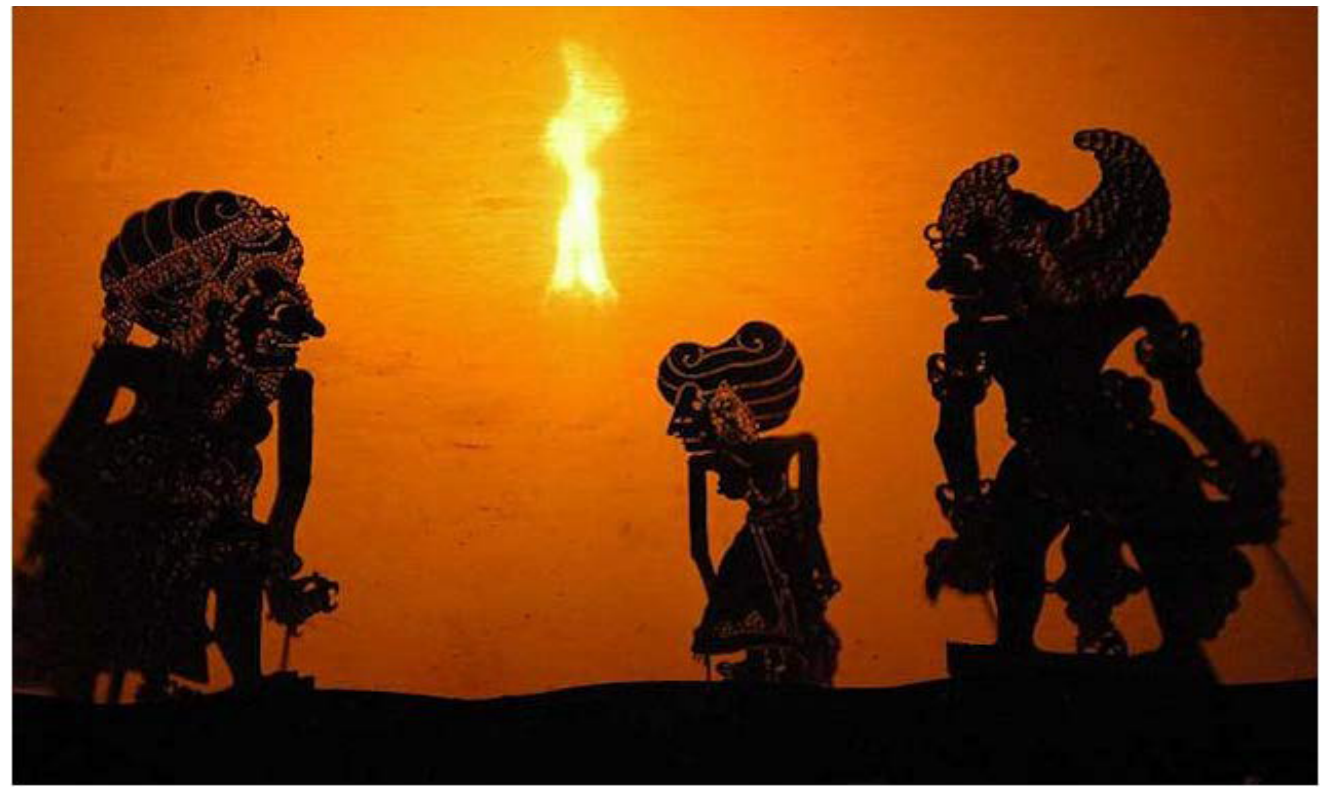

Figura 1: Cena do Ramayama

Fonte: https://creators.vice.com/en_us/article/z4qeza/traditional-indonesian-theatrical-wear-for-the-3d-printed-age. Foto: Rebecca Marshall sob licença de Attribution-ShareAlike 2.0 Generic.

Acesso em: 09 dez. 2017.

\section{A mise-en-scène total}

Craig planejou, na Itália em 1937, uma performance da Paixão de São Mateus de Bach sob a égide fascista (Innes, 2005, p. 72). O arranjo cenográfico fascista tem escala monumental, reside na ideia de ser imprescindível a comunicação eficaz entre a arte pública e a massa, que crie um juízo de valor entre os anseios do povo e o ideário fascista. Uma unidade que crie uma identidade. Christopher Innes, porém, entende que a tentativa desta empreitada foi mais por oportunismo do que por engajamento, pois Craig admirava Mussollini mais pela sua persona teatral do que o tipo de políti- 
ca que ele representava. Mussolini sonhava em construir um teatro com capacidade para pelo menos oito mil pessoas, num movimento político que almejava a reconstrução do império romano (Innes, 2005, p 72). Para Olga Taxidou (1991, p. 169), Mussolini criaria um grande império que inspiraria um grande teatro, e Craig seria o seu nome maior. A seminal revista The Mask, editada por Craig, sob vários pseudônimos, foi partícipe ativa na reverberação dessas ideias. Na edição de 1914 (vol. 6, no 14), ano do início da primeira grande mundial (1914-1918), Craig, mesmo sendo um cidadão inglês, esposava ideias em paralelo aos movimentos totalitários alemães e italianos. No epílogo, ele escreveu:

Tenho muito de Revolucionário em mim; não sou propriamente um. Minha revolta é contra a Revolta. Creio e almejo pela Ordem e a Obediência, tão natural quanto o caos e a falsidade. (Craig apud Taxidou, 1991, p. 71)

Taxidou (1991) observa que Ordem e Obediência tem uma conotação metafísica e não materialista, porém, para nós, Ordem e Obediência tem, neste contexto, também um caráter materialista que inspiram os grandiloquentes espaços cênicos de Craig, na necessidade de um líder encarnado, no encenador como herói carismático, o über-marionette como redentor artístico e a possibilidade técnica da reprodução dos seus cenários; a cinética impessoal, massiva e geométrica dos atores e, por fim, através da grandeza de sua arquitetura, Craig sugere uma manifestação física de um poder constituído, uma espécie de hiper-realismo envolto numa dinâmica totalitária.

Paradoxalmente, sua mise-en-scène tem um sentido não-retórico, declaratório, onde inexiste persuasão; o espectador escolhe o que contemplar, pode sutilmente ignorar ou atentamente olhar, perceber um ponto qualquer, um detalhe, uma fresta, sem arroubos. Na experiência simbolista, não se tenta explicar coisa alguma: nela, cria-se visões e Entendimento; e devem ser contempladas com os olhos da mente. Nesse sentido, quando trata dos espectros em Shakespeare, Craig assinala:

Em Macbeth, esses espíritos chaman-se, como nos contos de fada, as Três Feiticeiras, nome elástico que o público de teatro pode, de seu agrado, escarnecer ou tomar a sério. (Craig, 1963, p. 277)

A cena simbolista é o lugar das reminiscências. Platão (428/27-347 a.C.) declara em Fédon $(1973,249$ e-25oc) que o sábio é aquele que relembra o que vislumbrou no mundo das Ideias e é seu dever iluminar aqueles que estão na caverna da existência terrena. O teatro, nessa abordagem, é uma vereda onde nos apropriamos de nós mesmos, um lugar que se identifica, onde nos reconhecemos como unidade. Platão, na mesma obra, analisa este tema com a teoria da anamnese ou teoria da recordação: nela, a alma participa do mundo das Ideias em uma existência pré-terrena; reencarnado, traz gravado em si aquele universo. Neste sentido, conhecer é recordar, o conhecimento como recordação. Fundamental para o Simbolismo é a sugestão e não a declaração formal, direta ou explícita. É o velado estímulo que inspira e exorta à transcendência; sugerir, sem objetivar os fenômenos. Constantin Stanislavski (18631938), um insuspeito adepto do realismo teatral, reflete de forma arguta sobre o Simbolismo quando diz: "pertence [o Simbolismo] à supraconsciência, que começa onde 
termina o ultra-natural" (Stansilavski, (1989, p. 299); e que só quando a vida espiritual e física do artista em cena desenvolve-se naturalmente, normalmente, pelas leis da sua própria natureza, o supraconsciente sai dos seus esconderijos. A mínima violência contra a natureza e o supraconsciente esconde-se nas entranhas da alma, protegendo-se da grosseira anarquia muscular. Para Craig o poder da sugestão deve estar atrelado ao movimento, não ao 'pequeno gesto', ele não se detinha nas minúcias, pois eram inexpressivos, não seriam notadas. Em Craig, a mise-en-scène deve sugerir ideias, categorias, 'estados' e ambiências e nada que possa evocar individualidades, sua proposta cênica é, no fundo, uma cerimônia. A luz, os screens, as linhas são entidades aspirando por uma união mística. Para nós, Craig demanda uma espécie de introvisão, ou seja, a faculdade de assimilar a essência objetiva; que, por meio da sugestão, surgirão símbolos que instigarão determinados movimentos expressivos e autênticos até se alcançar o gesto simbólico.

Irène Eynat-Confino (1987, p. 25), entende que sugestão é um termo apropriado, da mesma forma que o termo expressão, ambos são o fundamento de um mesmo processo que tem como base os símbolos, estes que criam uma atmosfera misteriosa que induz a percepção e a revelação da Verdade e da Beleza. Para Lee Symons (apud Eynat-Confino, 1987, p. 45) o segredo usado por Craig foi o de transferir o padrão de determinado elemento por outro padrão que evoque esse mesmo elemento em sua mente, uma transferência de padrões em graus e também, uma nova 'qualidade'. Para Eynat-Confino, Craig chegava neste padrão pela seguinte contextualização: traduzia uma determinada experiência num "equivalente estético", por um processo de simplificação e implicação. Essa transferência de padrões, se nos apresenta como uma espécie de metáfora que por comparações implícitas advém um novo design, um novo padrão. O excelente crítico Arthur Symons que foi testemunha de algumas produções de Craig adverte que há um elemento incalculável na sua cena: uma parte acidental, outra parte inspiração. A questão pertinente é: Quanto é acidente e quanto é inspiração? (Craig, 1907, p. 349).

\section{A sombra expressiva}

Em 1876, em Bayreuth, templo artístico de Richard Wagner, devido a um problema técnico durante a apresentação da ópera wagneriana Rheingold o público ficou imerso na escuridão pela primeira vez. Uma desorientação circundou a plateia; nesse momento Wagner percebeu a potência do lúgubre como força expressiva tal e qual a luz. Neste contexto, o jogo luz-sombra torna-se eloquentes. A partir dessa influência, Craig, como Herkomer (1849-1914) não se rogaram em colocar seus atores na escuridão, esse conceito que atingiu envergadura com o expressionismo, como exemplo, é útil assistir o filme-referência do Expressionismo: O Gabinete do Doutor Calegari (Das Kabinett von Dr. Caligari, Alemanha, 1919), Direção de Robert Wiene, considerado um dos filmes clássicos do cinema expressionista, ao lado de Nosferatu (1922) e Fausto (1926) ou ainda, numa abordagem mais contemporânea, o uso inteligente da sombra por Marlon Brando no filme Apocalipse Now (direção de Francis Ford Coppola, roteiro dele e de John Milius, 1979, Estados Unidos). 


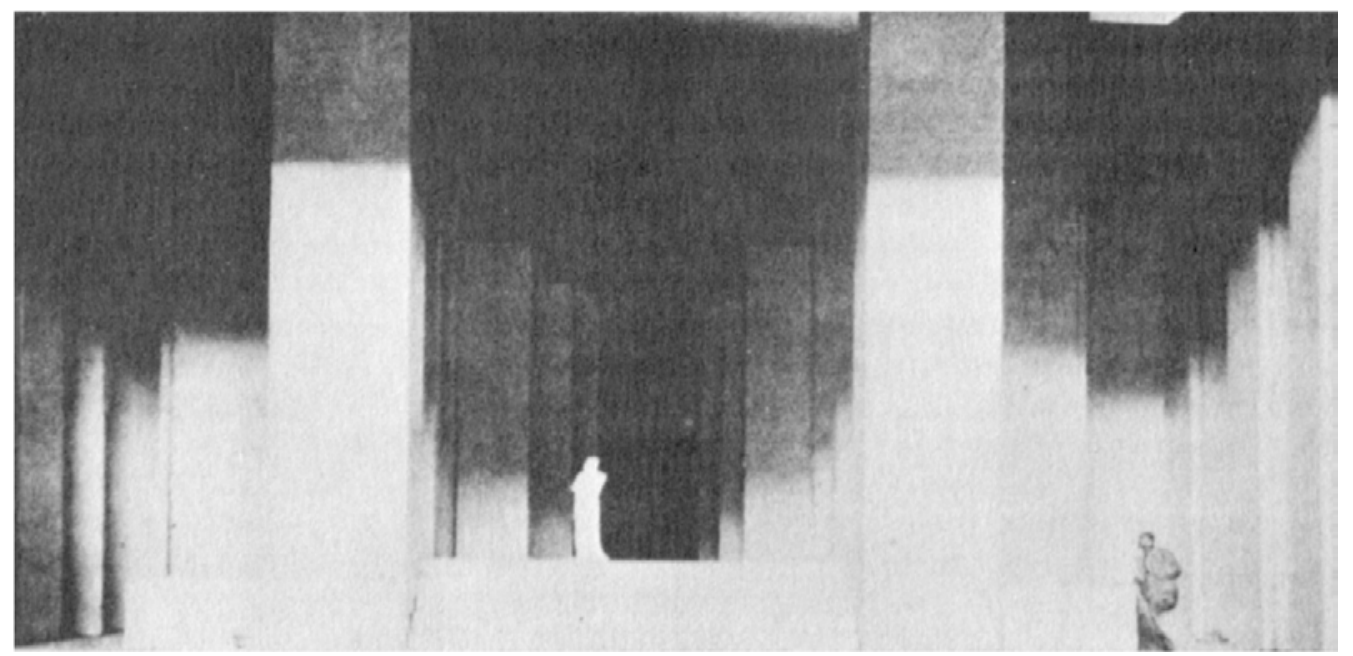

Figura 2: A sombra. Fonte: https://archive.org/details/cu31924026417984. Acesso em: 09 dez. 2017

Na figura acima, um estudo sobre os screens para o paradigmático Hamlet que Craig produziu junto com Stanislavski no Teatro de Arte de Moscou (TAM) em 1912, pode-se notar como a inserção das sombras é ostensiva, quase violenta (Craig, 1913, p. 84). Uma espécie de tenebrismo, um áspero contraste entre luz e sombra. O chiaroscuro, o contraste entre luz e sombra exige conhecimentos de perspectiva, dos efeitos que a luz provoca nas superfícies, no matiz. Áreas lúgubres valorizam o estudo cromático, a composição.

\section{Dido and Aeneas}

A temática clássica grega-romana é um tema recorrente em Craig. Entre as suas primeiras produções, Craig trabalhou com o mito em Dido and Aeneas (1899-1900), Acis and Galatea (1902), depois, a History of Dioclesian. O que atraiu Craig no drama grego, sugere não terem sido a singular maneira que o povo helênico retratava a realidade humana. Para ele, os gregos conseguiram captar uma pequena parcela do segredo do movimento; nesse sentido, o uso imaginativo de como eles integravam a natureza com a cena, o movimento do coro com o público e o movimento do sol sobre a arquitetura que 'movia' os espectadores. $O$ movimento exsurge através do olhar, ou ainda, o movimento se desenvolve concomitante ao olhar; "a beleza incomparável de se assistir um espetáculo que se desenvolve ao ar livre, o enredo, a narrativa move-se com a luz, as nuvens, enfim, com a natureza" (Craig, 1913, p. 8). Para o uso da luz natural é necessário um estudo apropriado, os gregos (e Craig) tinham essa percepção; no teatro, a iluminação cênica abriga a ideia de criar uma atmosfera propícia a um tipo de manifestação artística fundada nos símbolos. Ora difusa, ora concisa, lacônica até, essa luz produz um jogo de inter-reflexões propícias a estados intimistas. Assim, o espaço teatral e a assembleia - essa entidade concreta de indivíduos - transforma-se num corpus hermeticum que se compartimentaliza. Um simples feixe de luz, pode ser um símbolo em si mesmo ou revelar ou a indicar algo, tornar algo expressivo em particular. Os efeitos de luz e sombra valorizam a percepção do espaço. A não-uniformidade da luz, a baixa intensidade luminosa amaina os sentidos. Em sentido contrário, a maior intensidade. Nesta época, foram de grande 
valia para o teatro a criação dos spotlights; passíveis de regular o foco da luz, bem como os obturadores, o direcionamento e a instalação à distância.

No final do século XIX a luz elétrica já era comum nos teatros, as luzes de ribalta e das gambiarras se utilizavam desse recurso. Afirma Innes (1998, p. 22) que Craig no início de sua carreira, ator ainda, entendia a bi-dimensionalidade dos sets como falsos e que a luz a gás, devido a sua suavidade, desfocava o que se via, criando uma ilusão que Craig muito apreciava, reforçando a perspectiva (trompe-l'oeil) e dando profundidade a cena. Mesmo assim, afirma Innes (1998, p. 22), mesmo quando se tornou comum nos teatros à luz elétrica, Craig manteve muito do que ele aprendeu com Henry Irving (1838-1905), seu padastro e renomado ator e empresário teatral inglês. Na figura abaixo, uns croquis da seminal produção de Dido and Aeneas. O engenho de Craig na posição dos holofotes, os diferentes planos em que os atores e atrizes contracenavam, o lugar da orquestra, quase invisível, sugere uma influência do fosso da orquestra no Bayreuth Festspielhaus ${ }^{3}$ (Teatro do Festival de Bayreuth). Com o fosso, a atenção do público imerge totalmente para o que acontece em cena, por mais que a música esteja presente.

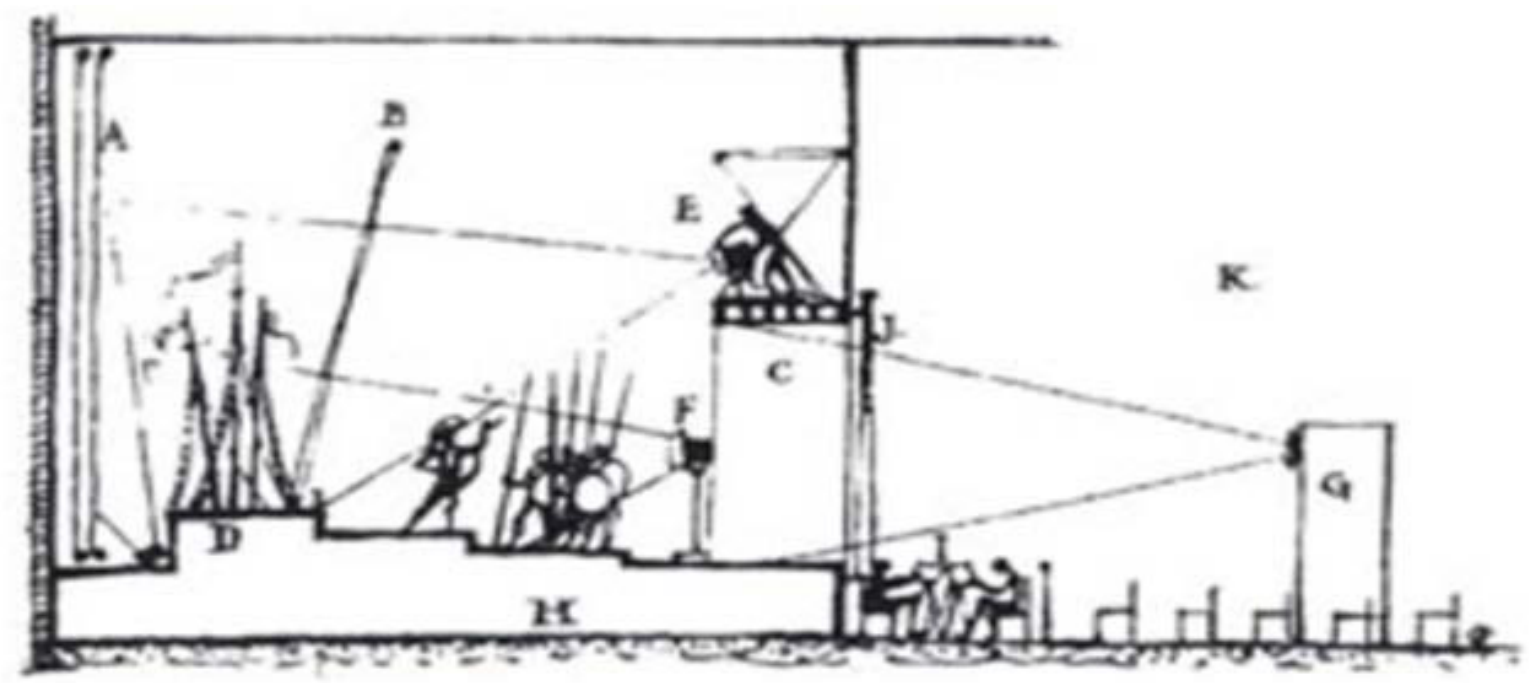

Figura 3: Ante-proscênio de Dido and Aeneas

Fonte: https://www.questia.com/read/1G1-198849225/herkomer-s-legacy-to-craig-and-the-new-stagecraft. Acesso em: 10 dez. 2017

Sob Craig, a luz sai de "lugar nenhum", circunda a cena num leitmotiv com sutis mudanças, criando um quê de infinito com sua perspectiva; uma aura propicia para uma cena fundada em signos. Da apresentação de Dido and Aeneas, marco da iluminação cênica moderna encenada por Craig, comentou-se:

Sob o efeito dessa luz, o fundo da cena torna-se profundamente azul, aparentemente quase translúcido, por onde o verde e o púrpura criam uma harmonia de grande encantamento. (Palmer, 2012, pp. 2-3)

Craig procura na própria natureza, seja no movimento dos animais, dos astros, elementos que pudessem de alguma forma contribuir para aquilo que deveria ser útil à sua estética. Em paralelo, procura um método científico para se atingir a Beleza.

${ }^{3}$ Bayreuth Festspielhaus é a casa de ópera usada para as apresentações das obras de Richard Wagner. 
Este atributo não significa somente harmonia, proporção ou simetria, mas, sobretudo, unidade; unidade de expressão, isto é, estilo. Um design por símbolos.

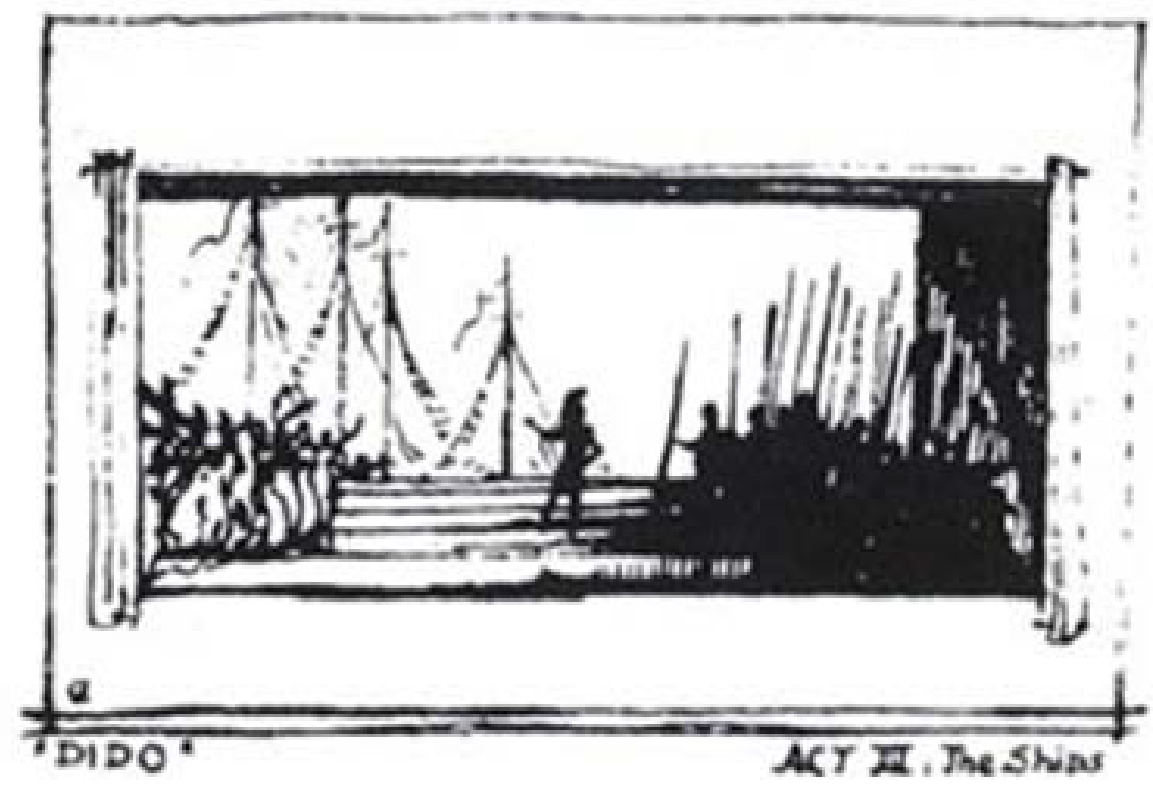

Figura 4: Dido and Aeneas

Fonte: https://www.questia.com/read/1G1-198849225/herkomer-s-legacy-to-craig-and-the-new-stagecraft Acesso em: 16 dez. 2017

Na figura acima, um sketch de Craig para o terceiro ato de Dido and Aeneas; Richard William Pick aponta para o evidente minimalismo, o jogo e o equilíbrio entre luz e sombra contra o pano de fundo e na ausência de luzes da ribalta. A preocupação na plasticidade da mise-en-scène. E o mais importante, afirma o autor que Craig não se influencia pelo realismo da cena de Herkomer e, sim, pela poesia da sua mise-en-scène. Outrossim, Craig faz uso da silhouette da sombra como força estrutural efetiva (Pick, 2008).

\section{A matiz pós-impressionista como pintura cênica}

Barnard Hewitt observa, no artigo Gordon Craig and Post-Impressionism (2009, p. 75), que Craig reconhece ser debitário de inúmeros pintores como Giotto, Rembrandt e Michelangelo, porém nenhuma menção faz aos pintores pós-impressionistas. Para o pesquisador, Craig inconscientemente absorveu e desenvolveu algumas características desta corrente artística. Entre os pintores dessa corrente, Cézanne, por exemplo, fez uso de simplificações geométricas como o cilindro, cones e esferas; por sua vez, Craig com seus biombos de diferentes tamanhos dava volume e profundidade à sua cena. Ainda, Cézanne foi um arguto observador dos elementos da natureza; criou um conceito baseado na visão binocular, que muito desenvolveu o seu trompe l'oeil, a perspectiva. A visão com os dois olhos, de forma autônoma, porém simultaneamente, é o que dá a impressão ou sensação de espacialidade, profundidade no campo visual. Craig instigando o espaço cênico, criando volumes, valorizando a profundidade espacial, a tridimensionalidade, com os seus biombos e iluminação alçou a mise-en-scène a um novo patamar. O palco, com esses elementos ganhou um 
novo elemento que ora dialoga, ora comenta e/ou ainda, contradita a cena. Cézanne entendia que a troca da luz e das formas evanescia a força dos objetos. O pós-impressionismo nasceu por entender o impressionismo ultrapassado, e é quase sempre assim a relação temporal das correntes artísticas. Mesmo assim, o pós-impressionismo sorveu das pesquisas dos impressionistas, a nova vanguarda se destacava por ampliar o estudo cromático e a composição, intelectualizam a representação por um novo modelo de representação. Outro ponto de contato com a percepção artística de Craig é o antinaturalismo de Gauguin baseado na convenção, no artificial. Craig preconizava uma nobre artificialidade, seja na mise-en-scène, na luz, no movimento, na articulação de todos os elementos inseridos na cena, sobretudo os atores, transformando-os, maximizando-os, na super-marionete.

Uma corrente pós-impressionista que sugere um maior contato com a concepção estética de Craig são os chamados nabis ${ }^{4}$ para eles a imagem só havia razão de ser se existisse um estilo, este que somente pode exprimir uma identidade. Exploravam o manancial puro da arte, diziam que as fontes deveriam dizer por si mesmas. No Simbolismo, o mote simbolista é pela percepção do invisível. Os nabis procuravam a beleza encontrada na natureza, eles aproveitaram o misterioso e místico mesmo nos assuntos mundanos. Na figura 5 abaixo, a obra A subida do Calvário (1889) de Maurice Denis, note que os ângulos convergem para a figura de Cristo. Criam uma espécie de desorientação, de perda dos sentidos, um declínio. Reforça esta ambiência o forte tenebrismo, usado como metáfora do suplício de Cristo.

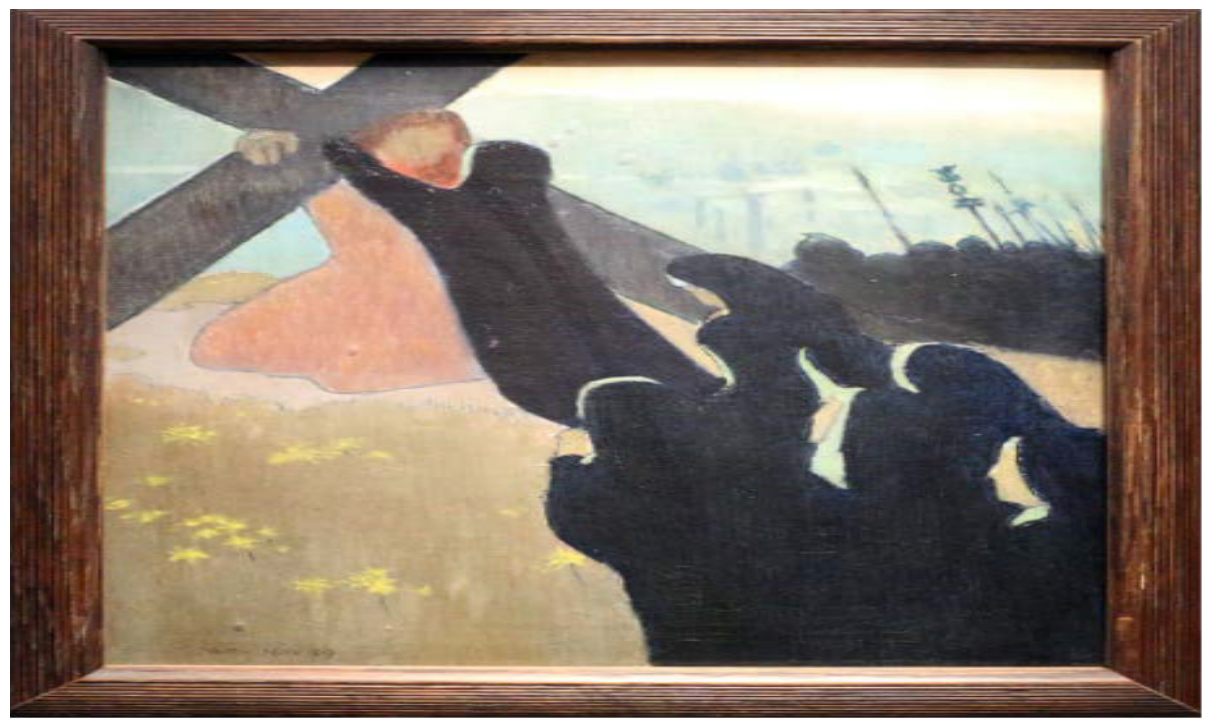

Figura 5: Nabis. https://en.wikipedia.org/wiki/Maurice_Denis\#/media/File:Maurice_denis,_salita_al_calvario,_1889.JPG Acesso em: 06 fev. 2018

Para Craig, a tênue iluminação, as silhouettes, o lúgubre, o movimento dos atores, por vezes, figurantes silenciosos, transformou a cena em espectral, transfigurada. Uma espécie de "cegueira intelectual", a visão como sinônimo de razão é um

${ }^{4}$ Corrente pós-impressionista de pintores, para eles a imagem só havia razão de ser se existisse um estilo, este que somente pode exprimir uma identidade, marca indelével, pessoal e intransferível de cada artista. Os nabis exploravam o manancial puro da arte, não entendiam ser necessário explicar os seus conceitos, diziam que as fontes deveriam dizer por si mesmas, além de Gauguin (1848-1903), e Cézanne (1839-1906), fizeram parte Pierre Bonnard (1867-1947), Maurice Denis (1870-1943), Maxime Dethomas (1869-1929), Meyer de Haan (1852-1895), Rene Georges Hermann-Paul (1864-1940). 
obstáculo à verdadeira percepção no contexto simbolista. A razão, neste sentido, é limitada e inapropriada até.

Em Craig, o estudo com a luz artificial repousa sobre os mesmos princípios de todos os elementos da cena, ou seja, estes devem ser harmônicos, buscando a unicidade (de únicos) e a unidade (de uno). O encenador não deve usar de sua inteligência somente em elementos práticos, ou seja, para ele, a luz deve ser resultado de um estudo e não somente da prática; o encenador deve estudar, usar sua inteligência em descobrir qual é o seu próprio modo de usar a luz. Craig é econômico quando o assunto é iluminação, talvez por ser algo que deva ser pesquisado por cada encenador, em cada projeto, cada produção, o importante é ter a sua feição, o seu design, restando implícita a ideia de que ele não tenha fórmulas prontas, acerca da iluminação cênica (Craig, 1957, p. 42).

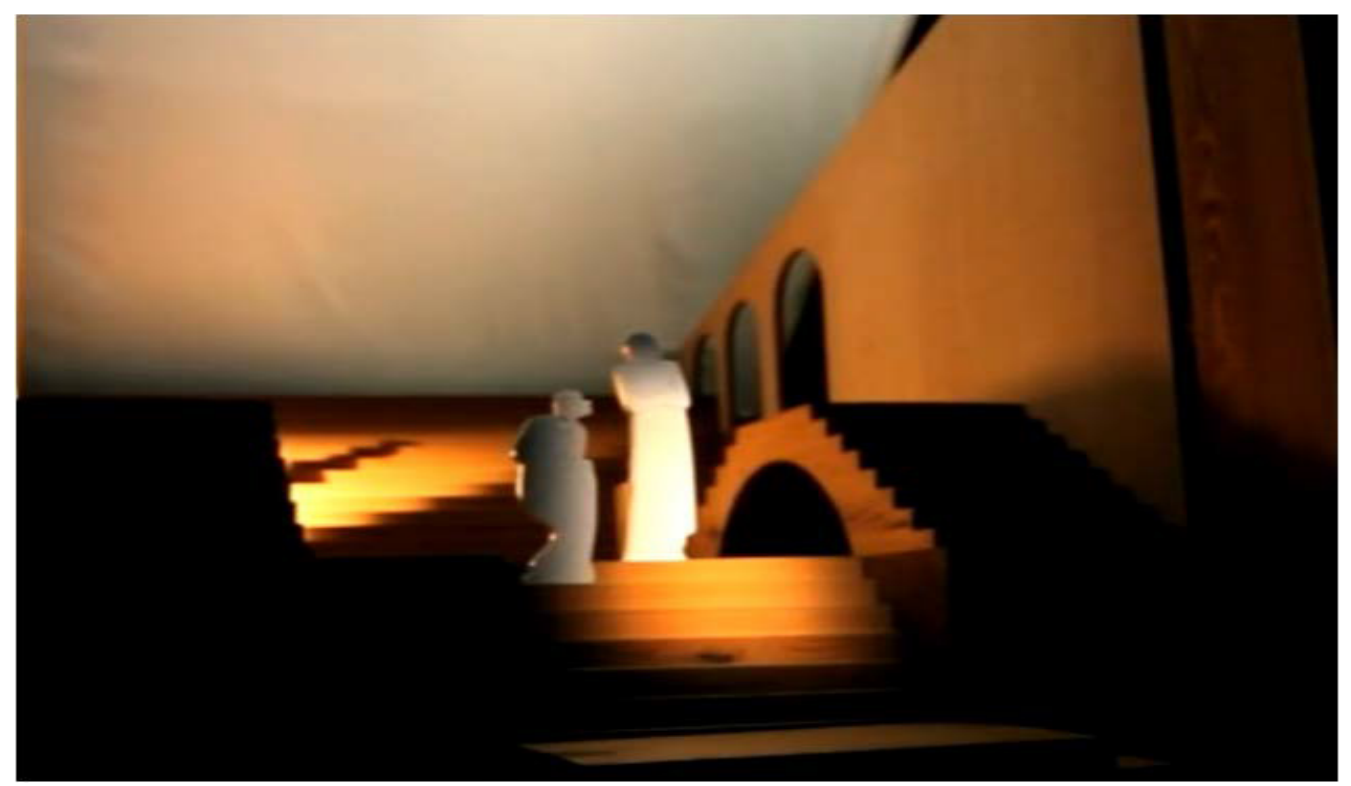

Figura 6: Interação com espaço e luz. Fonte: https://vimeo.com/35090396. Acesso em: 10 fev. 2018

Na figura acima, um olhar moderno sobre a iluminação de Craig, uma instalação interativa na mostra Space \& Light: Edward Gordon Craig exibida no período de março de 2010 a março de 2011 na galeria de Teatro e Performances do museu Victoria and Albert ( $V \& A$ ) em Londres. Abaixo da figura 6, o endereço de um vídeo editado que demonstra um visitante do museu manipulando as estruturas criadas por Craig e o seu jogo com as luzes e as sombras.

\section{Referências}

CRAIG, Edward Gordon. In: A Living Theatre: A Gordon Craig School, The Arena Goldoni, The Mask, Florença, 1913. Disponível em: https://archive.org/stream/ cu31924026123368\#page/n91/mode/2up/search/angle 
Edward Gordon, The Mask, Volume 6, número 14, Janeiro 1914, Disponível em:

http://bluemountain.princeton.edu/bluemtn/cgi-bin/bluemtn?a=d\&d=bmtnaau191401-01.2.7\&e=-------en-20--1--txt-txin-------

Edward Gordon. Towards a New Theatre. Londres/Toronto: J. M. \& Sons Ltda., 1913.

EYNAT-CONFINO, Irène. In: Beyond the Mask: Gordon Craig, Movement, and the Actor, 1987, Southern Illinois University, Board of Trustees, 1987.

HEWITT, Barnard. Gordon Craig and Post Impressionism. Quartely Journal of Speec. V. 30, n. 1, p. 75-80, 1944, Quartely Journal of Speech, vol. 30, no 1. P. 75-80. Disponível em:

http://www.tandfonline.com/doi/abs/10.1080/00335634409380954

INNES, Christopher. In: Edward Gordon Craig: A Vision of the Theatre. Harwood Academic Publishers. York University, Ontario, Canadá, 1998.

PALMER, Scott D. The Beggining of the Modren Stage: Edward Gordon Craig ant th eMay 1900 production of Dido and Aeneas. Artigo para a revista Focus, The Journal of the Lightning Designers, 2102, p. 2-3. Disponível em: http://eprints.whiterose. ac.uk/74746/7/EGCraig_and_Dido\%26Aeneas.pdf

PLATÃO, Fédon, Coleção Os Pensadores, Diálogos, 1973, Disponível em:

file://C:/Users/intel/Desktop/udesc/Platon\%20-\%20Fedon.pdf

PERSADA, Sangga Sarana. Performance of Wayang Kulit. 1997-2000, Disponível em: http://www.joglosemar.co.id/wayangperformance.html.

PICK, Richard William. Herkomer's legacy to Craig and the new stagecraft. Theatre Notebook, Oct. 2008, p. 126+. Academic OneFile. Acesso em: 12 dez. 2017.

SELENICK, Laurence. Gordon Craig's Moscow Hamlet: A Reconstruction. Greenwood Press. Westport, CT. 1982.

STANISLAVSKI, Kosntantin. Minha Vida na Arte. Tradução Paulo Bezerra. Rio de Janeiro: Civilização Brasileira. 1989.

SYMONS, Arthur. Studies in Seven Arts. New York: E. P. Duton and Co., 1907.

TAXIDOU, Olga. In: The Mask: A periodical performance by Edward Gordon Craig, 1991, (Contemporary Theatre Studies), Harwood Academic Publisher. 